\title{
Connectivity, Legibility and the Mass Image
}

\author{
Sean Cubitt
}

\begin{abstract}
Network connectivity should surely by now have already arrived at the global village. Instead, our only universal is the commodity form. To the extent that the actually existing global formation is universal, it does not constitute a culture. But if legibility is a hallmark of culture, the implication is that global connectivity is illegible. The humanities alone are equipped to identify what is truly illegible, a task we perform precisely by reading, using every technique we have, eclectically, to find an entry into the opacity of events. In this chapter, Sean Cubitt argues that connectivity has produced a universal mass image, and asks whether it is possible to restore legibility to it, and if so in what forms.
\end{abstract}

The transition of film and television as discrete theatrical and domestic experiences into ubiquitously available streaming video services brings a new form of exploitation and new aesthetics. Inhabitants of the wealthy North have become highly skilled but also highly disciplined consumers of the mass image. The most intense site of consumer discipline was created in the capitalization of the World Wide Web and the rise of app culture, which now shapes the vast majority of interactions as commodities. The network condition frames moving image media and structures the modes of thought involved in their analysis. The perpetual surfeit and constantly tailored feeds of images respond to these technical and economic formations. Connectivity under these circumstances is no longer a need or a pleasure but an obligation.

If Raymond Williams's thesis of culture as "a whole way of life" (1958a: XIV) were still true, network connectivity should surely by now have constituted a global village where cultural wholeness pervaded the species, or at least showed some signs of drifting towards it. Instead of culture, our only universal is the commodity form. To the extent that the actually existing global formation is universal, then, it does not constitute a culture. To the extent that legibility is a hallmark of culture, the implication is that the commodity form of global connectivity is illegible insofar as it is commodified. Humanities alone are equipped to identify what is truly illegible, a task we perform precisely by 
reading, using every technique we have, eclectically, to find an entry into the opacity of events. This essay argues that the aggregation of uncounted millions of commodified images comprises a single, universal mass image. It asks whether it is possible to restore legibility to images today, thereby returning them to culture, and if so, in what forms. If culture in Williams's sense is to become an option in our near future, such legibility - undertaken in the same Marxist and Leavisite traditions as he owned (Williams 1958b) - will be the necessary method for recuperating it.

\section{The Critique of Connectivity}

In place of the old wants, satisfied by the productions of the country, we find new wants, requiring for their satisfaction the products of distant lands and climes. In place of the old local and national seclusion and self-sufficiency, we have intercourse in every direction, universal interdependence of nations. (Marx and Engels)

Thus, Marx and Engels in the Communist Manifesto (1848), already prefiguring the challenge to legibility that we face today in their phrase "intercourse in every direction." As the humanities in the last quarter of the twentieth century gradually abandoned old canons of value based on a "civilization" more or less exclusively white, male and European, more positive terms like "connectivity," "network" and "entanglement" added themselves to the negative virtues of "resistance" and "subversion," inspired in part by Deleuze and Guattari's utopian concept of the rhizome (1967: $6 \mathrm{ff}$.). Today, however, the network condition is the site of a profound, even existential unhappiness. When many-to-many networks replaced one-to-many broadcasting, it was experienced as a liberation. Today, many-to-many has been replaced by the so-called social media mode of many-to-one communication. Not surprisingly, the "one" crumbles under its assault.

In the Communist Manifesto, capital's global connectivity creates new needs that require, for their satisfaction, colonialism, imperialism and the ongoing violence of accumulation by expropriation (Luxemburg 1951; Harvey 2010). Our new need for a newer smartphone depends for its satisfaction on the global networks of mining, fabrication, logistics, transport, retail, finance, debt and waste. In place of an older and perhaps poorer self-sufficiency, unhappy in its own way, we have universal connection by trade that produces new unhappinesses. The new connections disconnect us from the old locale. Networks of identity and lifestyle, peers and professions, 
trading partners and fandom overwrite and dissolve local social connections, just as they overwrite and dissolve the lives of populations displaced by mines, sweatshop workers and the desperate poor who pick over the dumping grounds of waste electronics. Branding makes these material networks illegible, burying the cultural forms of supply chains under the commodifying gloss of advertising and product design. Social media equally render illegible the disconnection of users from their material circumstances. Connection is also disconnection.

New needs are written over old desires. The connected individual is no longer herself, if "self" is a state where desire is shaped by its social repression. Network capital promotes a non-self liberated from socially and locally formed desire. In place of desire it prefers to posit Marx's "new needs," which are not repressed but rather stimulated in order to be plugged into an unstemmable offer of tailor-made satisfactions modeled on the needs that capital has produced. The self is ab origine alienated by repression. Rather than being freed from alienation, the consumerist non-self is doubly alienated: first, as the repressed, desiring self, created by socialization; and second, as the asocial non-self, alienated from the social whose repressions constructed it and its desire. Rather than freeing some original desire, the new need is constructed on its double alienation, as a satisfaction external not only to the self, but to the social. The repression that forms desire in its image is itself repressed in favor of a compulsory jouissance in the consumption of commodities. It is no surprise that this deracinated and doubly-alienated non-self yearns for and validates the very connectivity that has created it and its demand for networks.

The dream of a many-to-many constellation promised by the early internet failed to take the place of community when its actuality transpired as manyto-one. Promotional media encourage us to imagine smaller, more enclosed networks of parties and holidays, friendships and love affairs, in a community of the like-minded glimpsed in adverts and celebrity lifestyle reportage. We want to be connected to a place where people who would really appreciate $m e$ are already connected and waiting for me to join them. That is the fantasy. In reality, networks are immense technological infrastructures of optic fiber, server farms, satellites and transoceanic cables, microwave links and cellphone networks, RFID tags and barcodes, credit and loyalty cards, where machine-tomachine communication has already outstripped human-to-human communication (Cisco 2015: n. pag.) and it is impossible to distinguish between them. These networks are physically built, owned and operated almost universally by corporations. The information superhighway realizes Marx's fantasia on the construction of roads, in which he perceives 
... the extent to which the socially posited needs of the individual, i.e. those which he [sic] consumes and feels not as a single individual in society, but communally with others - whose mode of consumption is social by the nature of the thing - are ... not only consumed but also produced through exchange, individual exchange. (1973:532)

The peak moment of capital can be recognized when all social needs are fulfilled neither by communities nor by states but by capital. Roads are a social need, but they are also vital to capital when the falling rate of profit forces acceleration and massification not only of production but of distribution, and by the same token demands intense speeding-up of the physical act of exchange. All those minerals and sub-assemblies in our computers and phones, all the talent locked up in a completed movie, are nothing but costs to capital until they have been sold: the faster they are converted back into money, the better. Therefore, Marx argued, capital would eventually take over infrastructural projects like roads, railways and canals (and, in our time, communication networks). Needless to say, having paid the piper, capital calls the tune: networks that serve its needs are the highest priority.

At the same time, the single most desperate need of the a-social subject of consumerism is for a community to connect to. When capital took over the provision of social goods, it was not only infrastructures like railways and telecommunications that were commodified but access to them. We purchase communication, which once was a local, social good, as a commodity. Connectivity moves from social good to goods and chattels. Society itself becomes just one of those needs that "are satisfied through the exchange form" (Marx 1973: 532). Today, the very possibility of society, having been shattered by consumerist individualism, can only be reconstituted through commodity exchange.

Commodification depends on the constitution of the world as a concatenation of exchangeable objects that in turn depends on an ontology of objects. But their commodification unpicks the self-identity of objects on which that ontology depends. Under the division between use and exchange value, sign and attention value, and the implication of objects in one another and in their environments demonstrates their non-identity. The reality even of geology is split by the hyperreality of derivatives. The abstraction of behaviors and data from affects and relationships, and their simultaneous formal subsumption into commodities reduces all differences barring price differentials to the universal medium of exchange. Things are both themselves and their equivalence. In consumption, the social self is displaced by serial identities that never have to articulate, even within a single consumer. As recently as Solanas and Getino's manifesto of Third Cinema (1971), it was possible to aspire to address 
"the people." Woe betide the academic or politician who speaks that way now. The work of network connectivity is to proliferate differences: to replace the social and its repressions, which produce both norms and the refusal and perversion of norms, with an indifferent climate where every need is normative. The unity-in-difference of The People is no longer possible at any scale under these conditions. Connectivity substitutes for the sociable working of culture a market in acquaintance.

\section{The Mass Image}

Such is the nomos underlying the condition of the production, circulation and consumption of images in the twenty-first century. But images are also actions of the logos. To understand the conditions of legibility and illegibility, we can no longer resort to modernist categories of ontology (an image is itself and other than itself by definition), epistemology (there is no longer a self capable of knowing) or of phenomenology (the encounter of image and subject no longer occurs in their co-presence but rather in their mutual absence, each of them already alienated from any pure or impure claim to being). We must instead turn to the clash of nomos and logos, the order of the law as it dissects, distributes and brings syntax to the spirit, the Word that, in John's Gospel, was in the beginning, the word before flesh, before the separation of the light from the dark, the logos of primal mediation.

The energy needed to produce information has to come from somewhere. Any photograph is an act of destruction, the murder of the light that it documents. Unlike a drawn, painted or etched picture, making a photograph is traumatic. Even if laboriously set up and composed, a photograph rips a moment out of the flux of time. The truth it claims as a record of a moment comes at the price of no longer sharing the common fate of moments: change. In this sense, a still image is true to the extent that it is without meaning. It can only record and communicate a truth about the instant if it does not expound its significance. The being of the world, its truth, is outside of language. Drawing, painting and printmaking are significant acts that instruct us in the meanings of what they depict because they cannot avoid departing from verisimilitude in favor of style. In a photograph, contrariwise, whatever meanings it carries are properties of either the thing imaged or the person imaging (camera operator or viewer), not of the entity "photograph." So, many wonderful images made with the photographic apparatus are significant, but, like paintings, they are so to the extent that they abandon the claim to truth in favor of significance and to that degree abandon the calling of photography to realism, the "pencil 
of nature." The truth that "true" photographs lay claim to is the truth of an instant ripped from the universal flow.

Moving images are an intuitive attempt to heal this trauma and restore significance by supplementing each image with another. That the attempt has been fruitless is obvious from the fact that we are making movie after movie and still have not secured the significance of the world. Against the still photograph, its assassination of photons, its alienation from change, its wholesale adoption of nomos against logos and its traumatic flight subordination of time to Being; against all this, the moving image, by adding image upon image, sought to nurse the injured still back to health. But then moving images joined the proliferation of printed images and the electronic acceleration of circulation created the conditions for a new alienation: the mass image. Here, individual images lose their being, becoming instead ephemeral components of a far greater, even universal project.

After the attempt to heal it by the supplement of successive images and the modern art of motion between and within frames, the trauma of being that had triumphed in the still photograph returns in the collective, networked being of all images as facets of a single unchanging image of movement. At the same time, the condition of digital scanning and network latency is that the mass image of network media, although singular, is ephemeral. A selfie posted to Facebook risks a certain transcendence. In that instant of taking and posting, you exist. But you exist as a quantum fluctuation in a statistically normative ocean. You have no eternity: only the ocean is eternal. Selfies are obsessive performances of the self precisely because the self is in crisis. The ephemerality of selfies, which makes them trivial in the regime of the traditional image, is the true aggregation of self, an identity, a lifestyle choice, a node in the social graph, in the twenty-first century. The ephemerality of contemporary images is their saving grace.

The world we have is unhappy; thus, happiness depends on negating what is given to us as the world. Images negate the world in order to produce pictures that are more startling, richer, surer, more filled with meaning and more desirable than the world we have to inhabit. Even images of unhappy events attempt to heal them. An image, any image, still or moving, that aspires to unity, aspires to happiness. The proliferation of images is a different matter. The new photographic ensemble of smartphone cameras and network communications captures, distributes, proliferates and aggregates images in immense numbers at immensely condensed speeds. This multiplication and acceleration of recording and circulation sums up at stasis. When any image is exchangeable for any other, there is no longer any information or benefit to be gained from circulating more of them. Instead of negating the world, the mass production 
and exchange of images reproduces it in the form of its economic logic, drawing each image into the commodity form as a preliminary to subsuming every image into exchange, abandoning the cultural project of legibility in favor of atomic commodities subsumed into the ocean of exchange.

The snapshot poses itself as a unique instant in time. Considered alone, as a unique instance, that is what it is. This is the kind of photograph Roland Barthes (1980) talked about in the discussion of the picture of his mother: unique, precious, significant and a presence tied to an absence, a lost but nonetheless real moment of the past. But when it is shared in gigantic databases (which Barthes avoided by not publishing the photo) and placed in relations of exchange with every other image, and when it also shares its GPS, facial recognition, histogram and compositional parameters, it becomes not an instant but an instantiation: a pixel in a pattern, an entirely predictable efflorescence of the universal image. In the mass image, every unique image loses its uniqueness at the moment its timecode and date stamp allocates it a place in a chronological map of time, a calendar which is no longer time-based but the translation of time into the spatial cartography of the calendar. In the Timaeus, Plato described time as "a moving image of eternity": in the mass image, we see constructed an eternal image of movement. Plato dismissed images from The Republic, we might say, for the same reason Socrates dismissed writing: the trauma of separation marks the legibility of time as trace divorced from substance. The eternity of the mass image erases the mark of trauma in a perfected eidolon, leaving no space for even the diagram of eternity that time provided.

Even though the individual image acts by negating the world, mass proliferation of images produces a positive: its own existence. Mass imaging's reproduction of the world negates the single image's negation of the unhappy world. It does not replace the unhappiness of exploitation and commodity exchange, because it reproduces it. The mass image - the huge composite picture of the world which is being assembled in databases at Facebook, Microsoft, Instagram and Google - employs humans to produce a universe of image-commodities that we and others exchange, reproduce and consume. Each image taken negates the scene it captures and replaces it with an image. As the absolute number of images increases, the mass image replaces the entirety, the wholeness of the world, not just the unique scene. By the same token, a culture of compulsorily happy pictures necessarily negates happiness by replacing happiness with pictures. If there is one thing we know about happiness, it is that it is not single. The aggregate, singular, mass image negates happiness a second time by re-imagining it as normative, coherent, stable and universal.

A world of happy pictures is not a happy world, but it is unhappy in a new way compared to the unhappiness of the world it replaces. When each happy 
image is consumed and replaced by dissatisfied desire, the individual images comprising the mass image are ephemeral. "Ephemerality" suggests that the images that negate changing events by replacing them with object-like happy depictions ultimately negate themselves by disappearing. Ephemerality is the bubbling in and out of existence of consumable facets of a single, allsubsuming mass image. The goal of the mass image is perfect pictorial communication, the absolute triumph of nomos over logos. And yet such perfection is by definition entirely predictable and therefore incapable of producing information. From within the logic of the mass image, the becoming-other of images is decay: mere noise, externality. Viewed critically, it is the noise of the unpredictable generation of the new.

Negation, as the philosophers use the term, implies that things are incomplete, unstable, inconsistent. For many contemporary philosophers, things do not exist, because they contain in themselves reasons why they are otherwise than themselves. What we think of as things are multiplicities (in the Marxist tradition) or becomings (in the Bergson-Whitehead tradition). The problem of the traditional image, which negates only to replace, is that it replaces change with a thing, an image, that contains in itself the reason why it is so and not otherwise. To the extent that the unique image does exist, it loses the power to change. An image that $i$, is present: it is now (present) and it is here (presence). As a negation, an image puts its thing-ness in the place of something multiple and changeable, which it displaces. By occupying the present moment, and by extending that present moment across the entire lifetime of the image, an image, a still image, not only replaces things (multiplicities, becomings) but also replaces the kind of time in which things change. A painted paradise on a church wall promises to replace historical suffering with eternal bliss. Photography democratizes the eternal present that once belonged exclusively to the saints.

The price of eternity is the trauma analyzed above, but it can be achieved as style, although, as Cocteau said, "Style is the enemy of journalism." Expression, significance, beauty, the qualities of style that link it to subjectivity, are incompatible with its function as truth-bearer. The photograph as witness is forensic in its detachment, denying to the supreme subject of the mass image, the One who sees all, the possibility of taking that responsibility, which, for Benjamin (2003), constituted the legibility of history.

But even this witnessing is only feasible if and when the legible trauma of the excision from time is itself excised in the change of privilege from either journalism or style to circulation. In the 199os, there arrived, in the form of the world wide web, a distribution medium of immense power that had almost no barriers to entry, barring easily acquired HTML coding skills. The utopian 
moment of the early 199os combined cheap video with the publishing, distributive and interactive capabilities of the web. Only after the shake-out of the dot.com crash in 2001 did it become apparent that a handful of net-native companies, notably Google, Amazon and eBay, had begun to create business models derived not from magazines and broadcasting but from the net itself. Those models - user-tracking and recommendations - provided the basis for social media through simple but monopsonic platforms (Mejias 2013: 33-5). The result has been a landscape of tribes, as Maffesoli (1996) called them two decades ago, a fragmentary terrain of (often ephemeral) groupings around celebrities, catchphrases and brands, to which we donate our attention and creations, not only unpaid but self-funding consumers of a panoply of instantly obsolescent machinery and indifferent differences.

"Is it possible to differentiate between dominant and oppositional networks, for example? Or are they all so inextricably tied that even an analytical separation of them becomes useless," so asks Arturo Escobar (2008: 11). His questions raise others, and especially in our context the question as to whether it is possible to rescue an oppositional agency for images on dominant platforms like Facebook and Instagram. The first part of this question concerns whether network dissemination of images makes those images network media. Network media distinguish themselves in that they are in the first instance distribution media, where mechanical and earlier electronic forebears were first and foremost production media. Producing an image may well have ethical consequences for those involved - artists and their models, news photographers and the people they image - but those consequences may perhaps be diminished if the image is kept hidden, like Courbet's Source and certain sacred images (of which Courbet's may well be an example). Are we less guilty of what we fail to publicize? To have made the Abu Ghraib images made criminals of those who made them (Scarry 1985; Sontag 2003); what status then for those who distribute them? If the answer is that it is in some way less terrible to share than to produce, then the ethical power of network media to demand responsibility for both making and enjoying images is diminished. Or am I too squeamish? Is it okay to turn away, to say "there are some images I never wish to see," and so absolve myself of accountability for pictorial violence on the grounds that I didn't look? If instead of showing, I share not the image but its transport, creating a network graphic on torture rather than pictures, is the diagram a technique for presenting my implication in the guilty truth without actually seeing it? Does the illegible statistical eidolon free me of my obligation to the one who suffers?

The inference for connectivity as principle and dilemma to draw from this detour through infographics is that the network relation, which is best 
emblematized in diagrammatic rather than pictorial form, is that precisely because networks are not only self-documenting, they are also self-negating. A network node is a point of transit, not a terminus, even though, as nodes, each of us thinks of ourselves as terminal destination. Connectivity is entropic: in network topography, every point is equivalent and equidistant, like the cosmic dust that, the cosmologists tell us, the universe will ultimately become. In this condition, all differences are indifferent. To distribute images of degraded victims is to degrade them further; not to circulate makes clear that their degradation cannot be separated from that of the immediate perpetrators, those who issued the orders, and the political regime that encouraged both the torture and the images of it. Abu Ghraib was already synonymous with torture under Saddam Hussain. The degradation is not specific to any one party. All humanity is degraded in this degradation; all humanity owes an unpayable debt to those who suffered at Abu Ghraib. Yet a dispassionate diagram of the images' circulation, under the guise of meta-commentary, denies the conditions of debt arising from both circulating and not circulating. The images are intolerable not only because of their prolongation of torture, but because of the impossible ethical demand they place on us. The diagram is intolerable because it does not make that demand. Is it the case that the network condition of circulation in itself removes the ethical demand?

The same problem of non-identity I noted about objects, and the same scale of ethical demand, is also the case with nodes, with the same ethical implications. Here is Michael Dieter's thumbnail description of a smartphone:

Here, interfacing can include a range of active relations such as tap detection, fingerprint identification, the operation of cameras, microphones, gyroscopes, accelerometers, vibration mechanisms, operating systems, location services (GPS), Bluetooth and, crucially, the oscillation of lithium ions as battery life. (166)

If to this we add the operation of software, apps and the actions of the human user, including their relation to the space, physical and social, where they interact with the device, it is clear that the network node is itself a network, indeed a network of networks that includes the user's biography, the environmental implications and the supply chains that bring the various components together. Any concrete instance has always been the solid instantiation of an incalculable number of inputs. As network node, the human-device interface is also centrifugal, at best a momentary focal point through which biography and data flows draw themselves to an illegible point in order to diffuse again in multiple directions. The non-identity of the network node is produced as 
a network effect, a point traveling through time, and necessarily ephemeral, a compound lens assembled and disassembled on the fly to focus, conform and retransmit. This pseudo-self, like Descartes's pineal gland, is a channel for assembling and mutating, whose task is to supply idiosyncratic combinations and inflections to a system that otherwise is too deeply standardized to provide its own. This is the role of disciplined consumption, where street cultures and lifestyle groupings reconfigure the symbols that claim their attention, now a form of labor, in order to renew the circulation of commodified affects. This work of (re)processing symbols is indistinguishable from the work of code: illegible because it is not written for human comprehension, because it is not writing as text but writing as process and because there is no referent, no usevalue, only oceanic exchange. In this role, the non-self's value lies in the data it processes.

The work of disciplined consumption and prosumption is not only unpaid but demands investment in kit and connectivity. Here, it performs the only truly terminal task of contemporary capital and the last authentication of the historical self: to be the subject of debt. Debt is incurred by spending future earnings today. In the last instance, all debt must be repaid by the individuals that capital has created as its debtors, but the lonely hour of the last instance never comes. The moment when debts are finally reconciled, the moment when the commodified self will be finally realized, never arrives.

The self, perpetually deferred, is not identical with itself. But neither are networks. The networking experience is not an experience of network infrastructure, which today is characteristically hidden beneath shiny interfaces. Bots and cookies, Facebook's social graph, and Google's user profiles are encouraged by widespread ignorance of how the internet works, which is a function of "user-friendly" design and the universal disguise of and blindness to the physical labyrinth of cable, switchers, routers, servers and server farms we disingenuously refer to as "the Cloud."

\section{Against Connectivity}

Connectivity, which appears to us in fantasies of belonging, depends on the interactions of a corporate network, whose economics, politics and cultural forms are structured by the commodification of the social good. It is premised on and constructs non-identical and atomized subjects, psychologically, economically and environmentally predestined to pay in the future for its operation today. Connection is not a solution: in its current form, it is the problem. 
At the same time, it is vital not to confuse connectivity with implication. I have dropped the word "implication" into my text a few times already. Now it is time to define it. Latour argued in his Oxford lectures that networks are "a tool to describe something, not what is described" (2005: 131). His statement was not a statement about the internet, but about an ontology of the world as flux. The metaphor of networks took hold in the post-war Macy conferences. In its current form, it covers human artefacts like the internet, the de facto ontologies of the 21st century - ecological and quantum science - and the Market as quasi-natural emergent form underpinning all human relations and dominating contemporary political life. Latour's comment makes clear that the application of a technical metaphor to non-human realities is just that: a metaphor. As metaphor, it is a translation, a communication of incommensurable terms between languages and across time. For cybernetics, the translation problem would result in what Orit Halpern calls "a statistical grammar of prediction" (2014:51), of the kind that now dominates the day-to-day circulations of the internet. In engineering, however, metaphors and translations are performative. Connectivity translates a condition of statistical probability into the operating principle of packet-switching networks, which return the favor by providing a metaphor for themselves and for the financial trading that constitutes the larger part of internet communication today.

And yet there remains a "something" that we are trying to describe with our network metaphor, and which the internet as performative metaphor might be defined as attempting to describe. Of the available terms (entanglement, enfoldment and many more) I like "implication" because it catches at once the "pli" of Deleuze's Leibniz (1993) and the remnants of causality, while at the same time evoking just that ethical sense which I have argued is disabled by current network communications. Non-identity is only a problem when identity is the sine qua non of many-to-one networks and of the architecture of debt, that is, when it emerges from the construction of capitalist individuality. Ethical demands produce a special angst when they arrive at the point of individual responsibility, when individuality, like the family institution before it, is in crisis. In connectivity, there is no place for shared responsibility, which falls on the helpless shoulders of an individual self so constructed as not to be able to bear it. Implication indicates an alternative to this situation. Reversing debt's predetermination of an endlessly deferred but ineluctable future, we are all indebted to our ancestors and our planet, all implicated in one another.

Mediation implicates us not only in the doings of other humans but in the local and cosmic environment. Sunlight and rock, water and plants are media implicating us in the world. All the media we are implicated in implicate themselves in us. Historically, the free and open internet of the early 199os was 
built on an infrastructure that was anything but common. Enclosure of the digital commons was to that extent a foregone conclusion. But underlying the infrastructure of the internet lies an older, broader commons that combines physical processes with the accumulated technical know-how Marx called "the General Intellect," itself enclosed and privatized in technologies. These layers of commons and enclosure create the internal contradictions that at once provide a critical foothold in the network and an escape route from the isolation of the network condition, at once through recognition of the implication of each human in every other and through the natural and technological processes that the political economy of the contemporary network excludes.

Moving image cultures are inhabited by the network condition as much as they inhabit it. Film and media studies' embrace of larger fields of making, sharing, viewing and using moving images enrich our understanding of the networks they inhabit and in many senses constitute. Precisely for this reason, critique of connectivity and the mass image is becoming a pressing issue. The challenge of legibility is then to confront the loss of significance in the traffic in data, without, however, returning to a hieratic semantics grounded in the authority of God or Man. The space between significance and the asignifiant is not a void but a sliding scale. We have a long job of work ahead to distinguish a-signifying primal mediation from ordered communication, and both from what we must now inhabit, the insignificance of components of the mass image. Work at the level of the single image, its atypical and unstable grip on being and reference, and its always particular articulation with the connectivities it emerges from and impacts on is the particular and crucial political-aesthetic task of the humanities in the early twenty-first century.

With thanks to Roberto Mozzachiodi.

\section{Works Cited}

Barthes, Roland. La Chambre Claire. Paris: Gallimard, 1980.

Benjamin, Walter. "On the Concept of History." 1942. Selected Writings, Vol. 4, 1938-1940. Ed. Howard Eiland and Michael W. Jennings. Cambridge, MA.: Bellknap Press/Harvard UP, 2003. 389-40o.

Cisco. Cisco Visual Networking Index: Forecast and Methodology, 2014-2019 White Paper. Cisco Systems, 2015. Web. 15 Dec. 2017.

Deleuze, Gilles. The Fold: Leibniz and the Baroque. Trans. Tom Conley. London: Athlone, 1993.

Deleuze, Gilles, and Félix Guattari. A Thousand Plateaus: Capitalism and Schizophrenia. 1980. Trans. Brian Massumi. Minneapolis: U of Minnesota P, 1987. 
Dieter, Michael. "Dark Patterns: Interface Design, Augmentation and Crisis." Postdigital Aesthetics: Art, Computation and Design. Ed. David M. Berry and Michael Dieter. London: Palgrave Macmillan, 2015. 163-78.

Escobar, Arturo. Territories of Difference: Place, Movement, Life, Redes. Durham: Duke UP, 2008.

Halpern, Orit. Beautiful Data: A History of Vision and Reason Since 1945. Durham: Duke UP, 2014.

Harvey, David. The Enigma of Capital and the Crises of Capitalism. Oxford: Oxford UP, 2010.

Latour, Bruno. Reassembling the Social: An Introduction to Actor-Network Theory. Oxford: Oxford UP, 2005 .

Luxemburg, Rosa. The Accumulation of Capital. 1913. Trans. Agnes Schwarzschild. London: Routledge, 1951.

Maffesoli, Michel. The Time of the Tribes: The Decline of Individualism in Mass Society. London: Sage, 1996.

Marx, Karl, and Friedrich Engels. Manifesto of the Communist Party. 1848. Trans. Samuel Moore. Marx/Engels Selected Works, Vol. One. Moscow: Progress Publishers, 1996. 98-137.

Mejias, Ulises Ali. Off the Network: Disrupting the Digital World. Minneapolis: U of Minnesota $\mathrm{P}, 2013$.

Scarry, Elaine. The Body in Pain: The Making and Unmaking of the World. New York: Oxford UP, 1985 .

Solanas, Fernando, and Octavio Gettino. "Towards a Third Cinema." Afterimage 3 (1971): 16-3o.

Sontag, Susan. Regarding the Pain of Others. New York: Farrar, Straus and Giroux, 2003. Williams, Raymond. Culture and Society 1780-1950. Harmondsworth: Penguin, 1958.

Williams, Raymond. "Culture is Ordinary." 1958. Resources of Hope: Culture, Democracy, Socialism. London: Verso, 1989. $3^{-14}$. 